\begin{tabular}{ll}
\hline CURRENT & ISSN: 0973-4929, Vol. 13, No. (2) 2018, Pg. 180-182 \\
WORLD & Current World Environment
\end{tabular}

ENVIRONMENT Journal Website: www.cwejournal.org

\title{
Dust Air Pollution in Delhi: Creation of Artificial Huge Lakes for A Holistic Solution
}

\author{
PROFESSOR UMESH KULSHRESTHA \\ (Editor-in-Chief)
}

School of Environmental Sciences, Jawaharlal Nehru University, New Delhi, India.

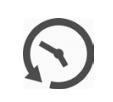

Article History

Published on $30^{\text {th }}$ August 2018

\begin{abstract}
Dear Readers
It is my pleasure to present this August issue of the Current World Environment before you. I thank all the authors, editors, reviewers and the office staff who have put all their efforts to bring out the issue in time. This issue has total twelve articles representing different types and topics. A review article reports the utilization of rice husk ash and its effect on the properties of concrete. There is a very important study reporting water quality of discharge from textile industries in Bangladesh. A case study reports the impact of Biomedical Waste in Cuttack in India. Other articles cover physico-chemical properties of soil in apple orchards, use of outdoor spaces, analysis of the International Responsibility System climate change, green space enhancement approach, crop yield study using domestic waste water etc. A case study reports the implications of $\mathrm{pH}$ in concrete pavement in Brazil.
\end{abstract}

The theme of my this Editorial is related to mitigation of dust air pollution in Delhi. It is well known that atmospheric dust loadings are very high in India especially in northern India'. Most of us know that the major sources of dust include construction activities, brick kilns, local soil suspension, resuspension of road dust during dry weather conditions ${ }^{2-3}$. In addition, the dust is also transported from the Thar desert and Middle east etc. through the trans-boundary and long-range transport sources ${ }^{4-5}$. In Delhi, ambient levels of the particulate matter are crossing the National Ambient Air Quality Standards (NAAQS) values most of the times6. Whether it is suspended particulate matter (SPM), $\mathrm{PM}_{10}$ or $\mathrm{PM}_{2.5}$, all are found to be more than their prescribed values resulting in very high values of Air Quality Index (AQI) which means very poor or unhealthy air quality. According to reports, approximate $100 \mathrm{~g} / \mathrm{m}^{2}$ per year dust fall takes place in Delhi region which is very high value on the global map $^{7-8}$

It is proposed to create of at least two artificial huge lakes $\left(\sim 5 \mathrm{~km}{ }^{\star} 5 \mathrm{~km}\right)$ one at Haryana border and other at

CONTACT Dr. Umesh Kulshrestha

umeshkulshrestha@gmail.com 9 School of Environmental Sciences, Jawaharlal Nehru

University, New Delhi, India.

(c) $($ )

(c) 2018 The Author(s). Published by Enviro Research Publishers.

This is an 6 Open Access article licensed under a Creative Commons license: Attribution 4.0 International (CC-BY).

Doi: http://dx.doi.org/10.12944/CWE.13.2.01 
UP border, in order to control dust air pollution in Delhi. We cannot ignore the fact that most of the ambient dust is emitted by the large area sources which cannot be controlled by any means used for tackling point sources. Dust and gaseous removal from ambient air of large areas needs a solution very similar to the natural process of dust removal i.e. wet scavenging (rain \& fog). Evaporation of water from these lakes will provide a moist atmosphere which will promote nucleation cleansing the air by removing the particles and gaseous pollutants through wet scavenging ${ }^{9}$. At the same time the occasional rains will keep soils wet so the soil particles are not resuspended into the atmosphere. This will help in reducing road dust and wind-blown dust fractions in the particulate matter. Road dust contributes around $56 \%$ of $\mathrm{PM}_{10}$ particles and around $38 \%$ of $\mathrm{PM}_{2}{ }^{5}$ particulate matter. Around 65 tons road dust is contributed every day in the ambient air of Delhi ${ }^{10}$.

Generally, tree plantation is considered as a very good option for air pollution control. Many people opine that the tree plantation will control the dust pollution. No doubt that the trees are good for ecosystem as they provide several benefits such as cooling, moisture, greenery, wood, medicines etc. There are reports that some selected trees are good for the removal of gaseous pollutants from outdoor and indoor air. But the scenario with particulate pollution is very different for trees. Our studies show that the dust fall is a nuisance for the plant folio because the deposition of dust particles clogs the stomates which in turn reduces the chlorophyll synthesis and chlorophyll content of the foliar ${ }^{11-12}$. The dust deposition on folio affects other biochemical properties of plants too. Our studies revealed that the trees were more stressed at high dust flux sites as compared at the site which had lower dust fluxes. Moreover, plants have their own emissions which ultimately contribute to fine and coarse particles. It means that tree plantation may invite a new problem related to increased levels of organic air pollutants.

I understand that the implementation of artificial lakes project is challenging especially the land acquisition but lesser challenging than the developing an industrial town or any other project which need huge natural resource utilization. These types of projects need the willingness of the governments. Such ambitious projects are COMPLETED with 'Let us START' mind set. Difficulties are always there which can be tackled from time to time during the process. However, it is a matter of debate how to go ahead and make it a reality. It needs discussions about the technicalities and impacts etc. involving various stakeholders such as policy makers, researchers, economists, academicians, businessmen, farmers, law experts and others who have to participate in the debates.

The question comes why it was not attempted earlier and elsewhere. The answer is that 'Jab jaago tab sabera' or better late than never. Osman Sagar and Himayat Sagar are the examples of such creation which have been very useful for the twin city of Hyderabad. In fact, in certain cases, India needs to explore its own the solutions for very local problems. Dust air pollution is considered a very local problem which can be solved by the local experts. I think that the Indian experts need to consider this proposal with an open mind to analyze its pros and cons. They should suggest necessary design and steps of actions in order to support its implementation after due discussions about their if and buts.

One should not forget that most countries have water all around. We have to differentiate the type of pollutants and their natural/anthropogenic origin. If the pollution sources are anthropogenic as the case of developed nations, it is easier to control the emissions at the sources that is why we could control CFCs. Moreover, these nations have seas all around; these regions receive rains round the year so their air is cleansed. The case of India is different where we have large area sources of dust which cannot be controlled by the method you use for any industrial or vehicular emission control purpose ${ }^{13}$. So the mechanism close to natural process is needed to control such very huge and continuous sources of dust that is why evaporation of water and nucleation of particles will help in scavenging the pollutants. Our research findings show a remarkable reduction in particulate $\left(\mathrm{PM}_{10}\right)$ matter during the rain resulting in a clean air conditions

However, on the other side, the atmospheric dust has been a boon for controlling acid rain in the region due to its buffering action which controls the acidity generated by the oxides of sulphur and nitrogen (mainly 
$\left.\mathrm{SO}_{2} \& \mathrm{NOx}\right)^{14-15}$. Atmospheric dust acts as a significant scavenger of $\mathrm{SO}_{2}$. In the presence of atmospheric moisture, the $\mathrm{SO}_{2}$ is oxidized by the $\mathrm{CaCO}_{3}$ content of the dust of this region forming calcium sulphate in the atmosphere. It means that total control of dust in air may lead to acidification problem in future.

Lake environment will help in reducing aridity and improving the micro-climate of Delhi region. Over a decade or so, perhaps there may be change in low-pressure pockets in northern India so the rainfall patterns too over different locations. Moreover, our need is to keep open soils wet which is again a large area which cannot be watered to make it wet but can be removed by the occasional rains due to the evaporation of water from the lakes. The lakes will help in recharging ground water levels and enhancing biodiversity as well. Lakes will also control desertification in the region. In fact, the creation of huge lakes will provide a long term and completely sustainable solution for the Delhi region.

\section{References}

1. Gupta GP, Singh S, Kumar B, UC Kulshrestha. Industrial dust sulphate and its effects on biochemical and morphological characteristics of Morus (Morus alba) plant in NCR Delhi. Environmental Monitoring and Assessment. 2015; DOI: 10.1007/s10661-015-4301-4.

2. Gupta GP, Kumar B, Kulshrestha UC. Impact and pollution indices of urban dust on selected plant species for green belt development: mitigation of the air pollution in NCR Dehli, India. Arabian Journal of Geosciences. 2016; 9: 136.

3. Kulshrestha U. Acid Rain. In Encyclopedia of Environmental Management; S.E.Jorgensen, ed. Taylor \& Francis: New York. 2013; Vol. I, 8-22.

4. Kulshrestha, UC, D Sharma. Importance of atmospheric dust in air: Future scope of research. Journal of Indian Geophysical Union. 2015; v.19 (2); pp: 205-209.

5. Kulshrestha U, Kumar B. Airmass Trajectories and Long Range Transport of Pollutants: Review of Wet Deposition Scenario in South Asia. Advances in Meteorology. 2014; doi.org/10.1155/2014/596041.

6. Kulshrestha UC, Reddy LAK, Satyanarayana J, Kulshrestha Monika Jain. Real-time wet scavenging of major chemical constituents of aerosols and role of rain intensity in Indian region. Atmospheric Environment. 2009: 43; 5123-5127.

7. Mishra M, d Kulshrestha U. Chemical Characteristics and Deposition Fluxes of Dust-Carbon Mixed Coarse Aerosols at Three Sites of Delhi, NCR. 2016. J Atmospheric Chemistry. 2016; DOI: http:// link.springer.com/article/10.1007/s10874-016-9349-1.

8. Sharma A, Singh S, Kulshrestha UC. Determination of Urban Dust Signatures through Chemical and Mineralogical Characterization of Atmospheric Dust fall in East Delhi (India). J Indian Geophysical Union. 2017; 21: 140-147.

9. Sharma D, Kulshrestha U. Spatial and Temporal Patterns of Air Pollutants in Rural and Urban Areas of India. Environmental Pollution. 2014; 10:1016/j.envpol.2014.08.026.

10. Sharma D, U.C. Kulshrestha. Dust storms and their influence on optical and chemical properties of aerosols along north-western Indo-Gangetic Plains, Journal of Indian Geophysical Union. 2017; v.21, no.6, pp: 526-534.

11. Sharma D, UC. Kulshrestha. Chemistry of atmospheric dust deposition and critical load assessment in the capital city of Delhi, India. Chemistry and Ecology. 2018; DOI: 10.1080/02757540.2018.1444036.

12. Tiwari R, Gupta GP, Kulshrestha UC. Summer time dust fall fluxes of reactive nitrogen and other inorganic species over the tropical megacity of Indo-Gangetic plains. Earth Interactions. 2016; DOI: http://dx.doi.org/10.1175/EI-D-15-0053.1.

13. Verma K, Kulshrestha U. Feasible Mitigation Options for Air Pollution and Traffic Congestion in Metro Cities. J Indian Geophysical Union. 2018; 22(2): 212-218.

14. Kulshrestha U. Acid Rain. In Encyclopedia of Environmental Management; S.E.Jorgensen, ed. Taylor \& Francis: New York, 2013. Vol. I, 8-22.

15. Sharma D, U.C. Kulshrestha. Chemistry of atmospheric dust deposition and critical load assessment in the capital city of Delhi, India, Chemistry and Ecology. 2018; DOI: 10.1080/02757540.2018.1444036. 